\title{
Aerosol Optical Thickness (AOT) mapping of Islamabad region using indigenously fabricated, locally-calibrated, economical sunphotometer and GLOBE sunphotometer
}

\author{
G. Raza1, 3*, M.A. Ashraf ${ }^{3}$, Shakir H. Qureshi ${ }^{1}$, N. Sarwar ${ }^{1}$, F. Shams ${ }^{1}$, Muhammad Imran \\ Shahzad ${ }^{2}$, N. Yasmin ${ }^{1}$
}

1. National Institute of Lasers and Optronics (NILOP), Nilore, Islamabad (44000), Pakistan

2. COMSATS Institute of Information Technology, Islamabad (44000), Pakistan

3. Department of Electronics, Quaid-i-Azam University, Islamabad (45320), Pakistan

${ }^{(*)}$ E-mail: grmangi@gmail.com

Received: 16/05/2018 Accepted: 15/04/2019

DOI: $10.7149 /$ OPA.52.2.51002

\begin{abstract}
:
This study aims at ground based atmosphere monitoring for Islamabad region $\left(33.7167^{\circ} \mathrm{N}\right.$ and $73.667^{\circ} \mathrm{E}$, $508 \mathrm{~m}$ altitude) using locally designed dual channels, (Green (550nm) and red (625nm)) LED based handheld sunphotometer. Calibration was done by using improvised transfer of calibration method employing pre-calibrated GLOBE (Global Learning and Observation to Benefit Environment) sunphotometer. Aerosol optical thickness (AOT) of said region for the month of July, August 2017 was calculated using acquired data for red and green channels. Matching trends (correlation up to 95\%) were observed for AOT obtained with GLOBE and local sunphotometer. AOT of Islamabad region generated by satellitebased Moderate Resolution Imaging Spectro-radiometer (MODIS) instrument board on AQUA and Terra satellites has also been presented for calibration period (Oct 2016-Feb 2017) to qualify our findings. The inter-comparison of data with MODIS instrument AQUA and Terra from Oct 2016 to Feb. 2017 with the local sunphotometer green channel yielded a correlation coefficients in range of 0.51-0.55 approaching the previously reported range values of $(\sim 0.55-0.60)$ for similar comparison. Along with AOT, in this study, the average daily Angstrom exponent $\alpha$, and angstrom turbidity constant $\beta$, have also been reported. The average of angstrom exponent for recorded data is 1.42 , this implies moderately polluted urban atmosphere of area under study, while the $19^{\text {th }}$ and $20^{\text {th }}$ July are clearest day for monitoring period with $\beta=0.07$ and $\beta=0.083$ respectively.
\end{abstract}

Key words: Aerosol optical thickness, AOT, GLOBE sunphotometer, angstrom exponent, atmosphere turbidity coefficient. MODIS

\section{REFERENCES AND LINKS / REFERENCIAS Y ENLACES}

[1] J.P. De Vroom, "Validation of MODIS aerosol observations over the Netherland with GLOBE student measurements," J. Geophys. Res., 111, D20311, (2006).

[2] Chiara Levoni et al., "Atmospheric aerosol optical properties: a database of radiative characteristics for different components and classes," Applied Optics 36(30) 8031-8041, (1997).

[3] IPCC. 2001. Climate Change 2001: The Scientific Basis. Cambridge University Press: Cambridge and New York. https://www.ipcc.ch/2001/

[4] J. T. Houghton et al., Climate Change 1995: The Science of Climate Change: Intergovernmental Panel on Climate Change. Cambridge Univ. Press (1996).

[5] J. Hansen et al, "Global warming in the twenty-first century: An alternative scenario," Proc. Natl. Acad. Sci., 97, 9875-9880, (2000).

[6] M. Granger Morgan et al., "Elicitation of expert judgments of aerosol forcing," Climate Change 75, 195214 (2006). 
[7] L. A. Remer, Y. J. Kaufman, "Aerosol direct radiative effect at the top of the atmosphere over cloud free ocean derived from four years of MODIS data," Atmos. Chem. Phys. 6, 237- 253(2006).

[8] H. Yu et al., "A review of measurement-based assessment of aerosol direct radiative effect and forcing," Atmos. Chem. Phys. 6, 613-666 (2006).

[9] Forrest M. Mims III, "Development of Inexpensive hand held, Light- Emitting Diodes (LED) based sunphotometer for GLOBE Program," J. Geophys. Res. 106, 4733-4740 (2001).

[10] B. N. Holben et al., "AERONET-A federated instrument network and data archive for aerosol characterization," Remote Sens. Environ. 66, 1-16 (1998).

[11] J.Y. Xin et al., "Aerosol optical depth (AOD) and angstrom exponent of aerosols observed by the Chinese Sun Hazemeter Network from August 2004 to September 2005," J. Geophys. Res. 112, D05203, (2007).

[12] Y. S. Wang et al., "Seasonal variations in aerosol optical properties over China," Atmos. Chem. Phys. Discuss. 8, 8431-8453 (2008).

[13] M. D. King et al., "Remote-sensing of cloud, aerosol, and water-vapor properties from the Moderate Resolution Imaging Spectrometer (MODIS)," IEEE Transactions on Geoscience and Remote Sensing 30(I), 2-27 (1992).

[14] X. Zhao et al., "Comparison and analysis of two aerosol retrievals over the ocean in the Terra/Clouds and the Earth's Radiant Energy System-Moderate Resolution Imaging Spectroradiometer single scanner footprint data Global evaluation," J. Geophys. Res. 110, D21208 (2005).

[15] Y.J. Kaufman et al., "Passive remote sensing of tropospheric aerosol and atmosphere correction for aerosol effect," J. Geophys. Res. 14, 102 (1997).

[16] M. D. King et al., "Remote sensing of tropospheric aerosols from space: Past, present, and future," Bull. Am. Meteor. Soc. 80, 2229-2259(1999).

[17] L. A. Remer et al., "Validation of MODIS aerosol retrieval over ocean," Geophys. Res. Lett., 29, (2002).

[18] D.G. Kaskaoutis et al., "Aerosol Monitoring over Athens Using Satellite and Ground-Based Measurements," Advances in Meteorology, 147910, (2010).

[19] Forrest M. Mims III, "How to monitor Ultra-violet radiation from Sun ," Scientific American 2, 263, 106109 (1990).

[20] Forrest M. Mims III, "An international haze-monitoring network for students," Bull. Am. Meteor. Soc. 80, 1421, (1999).

[21] Forrest M. Mims III, "Sunphotometer with light emitting Diode as spectrally selective detector". Applied Optics 31, 6965-6967 (1992).

[22] Carlson, Shawn., "Hazy Skies are Rising," Scientific American 276, 106-107 (1997).

[23] D. R. Brooks, Forrest M. Mims III, "Development of an inexpensive handheld LED based sunphotometer for the GLOBE program," J Geophys. Res., 106, 4733-4740 (2002).

[24] Kings et al., "Cloud and aerosol properties, perceptible water and profile of temperature and water vapour from MODIS," IEEE Transactions on Geosciences and Remote Sensing 2,41, (2003).

[25] Ichoku et al., "Golbal aerosol remote sensing from MODIS," Adv. Space Research. 34, 820-827 (2004).

[26] Tanre et al., "Remote sensing of aerosol data over ocean, using MODIS/EOS spectral radiance," J. Geophys. Res. 102, 16971-16988 (1997).

[27] L. A. Remer et al., "The MODIS algorithm, products and validation. Journal of Atmospheric Sciencesspecial section," 62, 947-973 (2005).

[28] De Meij et al., "The sensitivities of aerosols in Europe to two different emission inventories and temperature distributions of emissions," Atmos. Chem. Phys. 6, 4287-4309 (2006).

[29] Q.Xu. et al., "Improving Aerosol Retrieval Accuracy by Integrating AERONET, MISR and MODIS Data" In: $8^{\text {th }}$ international conference on information fusion, Philadelphia, (PA) (2005).

[30] Y. J. Kaufman, "Aerosol Optical Thickness and Atmospheric Path Radiance. Laboratory for Atmospheres, NASA Goddard Space Flight Center, Greenbelt, Maryland," J. Geophys. Res. D2, 98, 26772692 (1993).

[31] T. F. Eck et al, "Wavelength Dependence of the Optical Depth of Bio Mass Burning," Urban, and Desert Dust Aerosols. J. Geophys. Res. D-24,104, 31333-31349 (1999).

[32] A. S. Zakey et al., "Atmospheric Turbidity Over Egypt," Atmos. Environ. 38, 1579-1591 (2004). 
[33] G. Raza et al., "Remote Sensing of Lower Tropospheric Aerosols and Clouds over Islamabad Region Using a Self-Engineered Mie Scattering Lidar," Atmospheric and Oceanic Optics 31(VI), 650-655 (2018)

[34] M. Hess et al., "Optical Properties of Aerosols and Clouds: The Software Package OPAC," Bull. Am. Meteor. Soc. 79( V), 831-44 (1998).

[35] B. N. Holben et al., "An emerging ground-based aerosol climatology: Aerosol Optical Depth from AERONET," J. Geophys. Res. 106, 12 067-12 097 (2001).

[36] 0. Dubovik et al., "Variability of absorption and optical properties of key aerosol types observed in worldwide locations," J. Atmos. Sci. 59, 590-608 (2002).

[37] O'Neill., et al., "Optical properties of boreal forest fire smoke derived from Sun photometry," J. Geophys. Res. 107, 4125 (2002).

[38] T. F. Eck et al., "High aerosol optical depth biomass burning events: A comparison of optical properties for different source regions," Geophys. Res. Lett. 30(XX), 2035(2003a).

[39] E. J. McCartney, Optics of Atmosphere. (1976), John Wiley \& Sons, New York.

\section{Introduction}

Natural or Anthropogenic Aerosols play a significant role in determining climatological patterns by influencing directly and indirectly the phenomenon like cloud formation- composition \& life cycle, sunlight transmission through atmosphere, temperature and humidity changes etc. [1,2]. Global average radiative forcing, of aerosols is expected to be equivalent in magnitude to the radiative forcing of about $2.4 \mathrm{Wm}-2$ by anthropogenic greenhouse gases [3]. Limited knowledge of optical properties of aerosols is the biggest hurdle in evaluating their effect $[4,5]$ resulting thus in a large uncertainty regarding the aerosol overall radiative forcing $[6,7,8]$. Thus continuous monitoring of aerosols is essential for better understanding of these processes and assessment of the effects of human activity on atmospheric constituents. Some ground based aerosol monitoring networks e.g Global Learning and Observation to Benefit Environment (GLOBE) [9], Aerosols Robotic Network radiometers (AERONET) [10], and sunphotometer network in china [11,12]. etc. and few satellites based monitoring devices such as Moderate-resolution Imaging Spectro-radiometer (MODIS) on AQUA \& Terra satellites $[10,13]$ try to serve this purpose. Although many problems related to satellite observations of aerosols have been resolved by sophisticated instruments nowadays, there are still problems as shown by discrepancies between different satellite products [14]. Traditionally ground based measurements are considered more accurate $[15,16]$ and often, satellite derived AOT values and accuracy of underlying data analysis algorithms are validated by comparing them with ground based data like AERONET [17]. Additional issues like limited temporal and spatial resolution and variable surface reflectivity in complex terrain also reinforce the necessity of ground based monitoring. The AERONET an aerosol-monitoring network was developed by NASA for measurements at global scale with the same aim of measuring Aerosol Optical Thickness (AOT) and study its impact on global climate. AERONET or any other Monitoring system characterize atmosphere in term of aerosol optical depth (AOD) or aerosol optical thickness (AOT) which is defined as the integrated extinction coefficient over a vertical column of unit cross section, a dimension-less figure of merit [3]. The coverage of existing ground based monitoring networks (like AERONET) has considerably augmented over the years but still today there are many major cities like Islamabad capital of Pakistan devoid of such ground based aerosol monitoring facility.

Remote sensing group of National Institute of Laser and Optronics Islamabad aims to develop such aerosol monitoring network at national level. This network will not only provide data over Islamabad but will span over entire country. In the first leg of this project we tried to design reliable, economical and rugged sunphotometers and employ these devices for continuous monitoring of Islamabad region for more than year. Sunphotometer, the most frequently used monitoring device measures the intensity of a direct beam of sunlight [18]. Sunphotometer offers an economical, rugged, and easy to handle solution for ground based aerosol measuring networks. In conventional sunphotometers, photo detectors with narrow- band pass filters (a few $\mathrm{nm}$ ) were used, but these filters are quite expensive, fragile, and subject to random failure. Light Emitting Diode (LED) is a good replacement of photo detectors and interference filters and it requires very simple electronics [19]. Although LEDs have spectral band pass relatively large (a few tens of $\mathrm{nm}$ ), but they are cheap, virtually indestructible, and very stable over the time [20]. LEDs were first used as detectors of light in sunphotometer by Mims, Forrest in 1992 [21]. The first LED-based Visible Haze Sensor was designed and developed by Mims, Forrest and TERC in 1996 [22]. A comparison study of the two-channel 
LED sunphotometer was published in 2002 by Brooks and Mims [23]. In this paper we have presented the Aerosol Optical Thickness/Depth (AOT/AOD) data over Islamabad for selected days of calibration period (Oct. 2017 to Feb. 2017), and July 2017, August 2017 using indigenously developed LED based sunphotometer and pre-calibrated GLOBE sunphotometer. This ground based simultaneous monitoring of AOT with indigenously developed sunphotometer and pre-calibrated GLOBE sunphotometer over Islamabad is first of kind.

Apart from introduction (section 1) this article is comprised of two parts section 2 describes designing and calibration method of sunphotometer, and section 3 discusses the Aerosol Optical Thickness (AOT) and its analysis. The AOT has been measured with a two channel handheld sunphotometer (indigenously developed) from the direct detection of sun light. The obtained data for calibration period, July 2017 and August 2017 has been compared with the pre-calibrated GLOBE sunphotometer results. The comparison with MODIS (onboard AQUA and Terra Satellite) AOT data has been performed for data of calibration period.

\section{Theory and Calculations}

\section{2.a. Area under Investigation}

The area under investigation, Islamabad is shown in map of Pakistan in figure.1with an inner circle. Islamabad is the capital of Pakistan $33.7167^{\circ} \mathrm{N}$ and $73.667^{\circ} \mathrm{E}, 508 \mathrm{~m}$ altitude. Islamabad has a humid subtropical hot summer climate that is mild with dry winters. Maximum temperature reaches to $46 \mathrm{C}$ in June and minimum temperature around $-3^{\circ} \mathrm{C}$ in ذanuary. Islamabad gets hold of an average of $1142.1 \mathrm{~mm}$ of rainfall per year. Islamabad with an area of 1,165.5 $\mathrm{km}^{2}$, population of the city is around 1,950,000 of which $66 \%$ is urban, having moderate urban growth rate and the problem of moderate air pollution owing to heavy traffic and other anthropogenic sources like industries and stone crushers on Margalla hills, in its vicinity. It also has the strong environmental effects of nearby Rawalpindi city, which is very densely populated with heavy traffic. There are only two AOT measuring stations of AERONET network in Pakistan at Lahore and Karachi and satellite data of AOT is also very limited due to fewer numbers of overpasses over the region. Hence this work is very significant for atmosphere profiling of area under study.

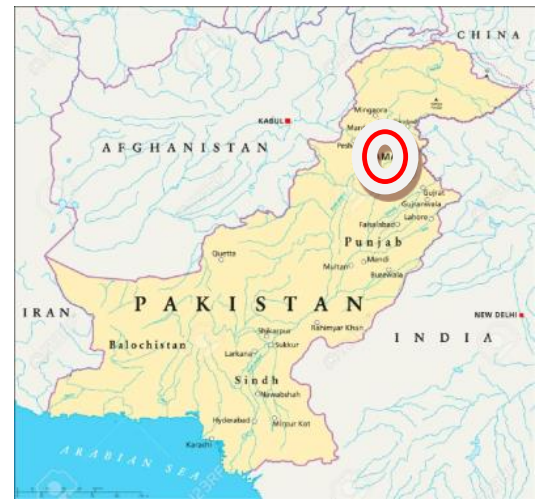

Fig.1: Geographical location of Pakistan and Islamabad, the study area

\section{2.b. Instrument Design}

The block diagram of indigenous developed and ingeniously calibrated, two channel hand held instrument is shown in figure 2. It uses the same custom-designed printed circuit board and case as that of the GLOBE visible light sunphotometer. The large dimension $(4 \times 9 \times 17 \mathrm{~cm})$ of thick plastic casing of sunphotometer to accommodate its small PCB mounted circuitry serve two purposes, 1 . Prevention of multiply scattered light to strike LED head on. 2. The electronics remain protected from speedy change in the temperature for duration of measurement. Further measures to reduce temperature effects are also taken such as minimal possible exposure to sunlight and continuous temperature monitoring during measurement. Two 5.0-mmdiameter holes at the upper end allow sunlight to enter and strike the two detectors whose active surfaces are about $7.7 \mathrm{~cm}$ away. The full angle field of view (FOV) of the LED is restricted to $1.2^{\circ}$. The FOV depends upon the size of aperture for light at the top of the casing and path length of light from aperture to LEDs. The designed instrument, measures the attenuation of the direct sunlight as it passes through the atmospheric mass. For precise alignment of sunphotometer straight toward the sun two L-shaped brackets 
containing holes are attached to right side of sunphotometer casing at the top and bottom ends with holes of brackets facing each other, coaxially. The brackets are attached in such a way that LEDs inside the sunphotometer receive maximum light when sunlight gets through the two holes of L-shaped brackets simultaneously as sunphotometer is pointed towards the sun. The original case temperature was maintained within prescribed limits $\left(20-25^{\circ} \mathrm{C}\right)$ at the start of each measurement set. Each detector produces a small photocurrent when impinged by light within its spectral response bandwidth. A 9-V battery powered dual operational amplifier (LM358). A variable feedback resistance is used in the circuit that converts this tiny current into voltages which is further measured by a digital voltmeter in a range of roughly $0.5-3.5 \mathrm{~V}$ in full sunlight. When the sunphotometer is pointed towards the sun, sunlight falls vertically over the head of the LEDs. A toggle/selector switch is used for green or red channel selection.

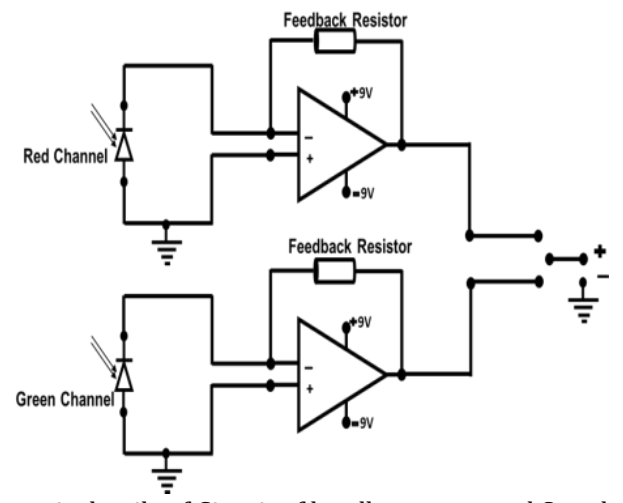

Fig.2. Schematic details of Circuit of locally constructed Sunphotometer.

\section{2.c. Theory and Methodology}

\section{i) AOT Retrievals}

The total atmospheric optical depth " $\tau$ " consists of three basic parts: molecular (or Rayleigh) scattering " $\tau_{\mathrm{R}}$ " by the atmosphere, atmospheric absorption by gases " $\tau_{\mathrm{g}}$ " such as ozone and scattering by aerosols

" $\tau_{\mathrm{a}}$ " (Aerosol Optical Thickness, AOT). In short we can write;

$$
\tau=\tau_{R}+\tau_{g}+\tau_{a}
$$

Aerosol optical thickness is given by the formula

$$
\tau_{a}=\frac{\left[\ln V_{0}\left(\frac{r_{0}}{r}\right)-\ln (V)-\tau_{R}\left(\frac{p}{p_{0}}\right) m\right]}{m}
$$

Here:

$V=$ channel voltage corresponding each of the two channels in $\mathrm{mV}$

$V_{0}=$ the extraterrestrial corresponding each of the two channels in $\mathrm{mV}$.

$r_{0}=$ average earth-sun distance

$r=$ earth-sun distance at the time of measurement

$\tau_{a}=$ aerosol optical thickness (AOT)

$\tau_{R}=$ Rayleigh scattering

$p_{0}=$ standard air pressure at sea level $(1013.25 \mathrm{mb})$

$p=$ air pressure at the observing site in $m b$

$m=$ relative air mass

$$
r=\frac{\left(1-\varepsilon^{2}\right)}{1+\varepsilon\left(360^{0} \times d / 365\right)}
$$

is the distance of sun from earth in astronomical unit, $\mathrm{d}=$ serial number of day of year (Julian Day) and $\varepsilon=$ 0.0167 , eccentricity of earth' orbit

While most of the above mentioned quantities are simple, two important quantities requires further description. 
ii) Relative air mass measurement $m=\sec \theta$

The Relative air mass (m) is a measure of the total content of atmosphere through which a beam of sunlight travels. Here $\boldsymbol{\theta}=$ solar elevation angle is either measured by $\theta=\tan ^{-1}\left(\frac{y}{x}\right)$, (where " $y$ " is the height of angle bracket, " $x$ " is the shadow length measured from scale) or using more detailed relation as found in different literatures e.g. by Mims [9].

\section{iii) Extraterrestrial constant $\left(\mathrm{V}_{0}\right)$}

Sunphotometer is considered to be calibrated if its extraterrestrial constant is known. This is the voltage which would be measured with sunphotometer if there were no atmosphere between experimental place and the sun i.e. at zero mass of air. Simplest and most approved technique for $\mathrm{V}_{0}$ calculation is Langley plot method. Extraterrestrial constant $V_{0}$ determination through Langley plot is mere extrapolation of voltage versus air mass graph in clear atmosphere.

\section{2.d. Data Acqusition}

Operational simplicity of sunphotometer means that measurement with sunphotometer can be taken within two to three minutes of sunlight exposure without meaning full temperature variations to effect reading. All the observations were carried out during clear sky conditions, which imply the cloud-free days or the intervals of the day that were cloud-free. The measurements were made after every 30 minutes 09:00h to 16:00 h local time with both Local and GLOBE sunphotometers simultaneously. The meteorological parameters, temperature (Temp.), relative humidity (RH\%), and accumulated rainfall (RF), were also recorded. in this paper data recorded daily for a period of July 2017 and August 2017 over Islamabad region with both, the indigenously fabricated and GLOBE sunphotometer is presented.

\section{2.e. Verification through satellite data}

The validation and verification of calculated AOT was performed by comparison of AOT obtained through ground based sunphotometers and satellite based AOT calculation for the same region. Different sources of satellite based AOT are available but MODIS data is most commonly employed as standard.

The MODIS aerosol Product monitors the ambient aerosol optical thickness over the oceans globally and over a portion of the continents. This instrument is on board NASA's Earth Observation System (EOS) AQUA (EOS PM) and Terra (EOS AM) satellite [23]. EOS satellite has Orbit at $705 \mathrm{Km}$, with a swath width of 2330 $\mathrm{Km}$, Scan rate 20.3rpm. MODIS acquire data at 36 spectral bands to give atmospheric, oceanic and terrestrial information [24,25]. MODIS measures AOT over land by recording reflection of residual at the top of atmosphere and uses 2.1- $\mu \mathrm{m}$ channel for it. But its data is considered more accurate over ocean than on land $[15,26,27]$ data accuracy is also compromised for complex Terrain in leading to large bias in models and need to have ground base observations [28]. With temporal resolution of 1 day, Level 2 data are produced at the spatial resolution of a 10x10/-km (at nadir). Overpass intervals of Terra and AQUA satellite over Islamabad and orbital tracks were obtained from its online web source. There are two MODIS daily Global data product files: MOD08_D3, containing data collected from the Terra platform; andMYD08_D3, containing data collected from the AQUA platform for combined deep blue and dark target for $550 \mathrm{~nm}$ channel.

\section{Results and discussion:}

\section{3.a. Calibration period results}

LED-based sunphotometers pose challenges for calibration and interpretation because their relatively wide spectral response prohibits indiscriminate application of the Beer Lambert Bouguer law. The GLOBE Sunphotometer employed in this study was pre-calibrated at Mauna Loa Observatory (MLO), the premier site for calibration because of its stable meteorology. The values of extraterrestrial constants, $\mathrm{V}_{0}$ of the reference GLOBE sunphotometer (Serial No; RG8-979) for red and green channel were $1535.6 \mathrm{mV}$ and $1728.8 \mathrm{mV}$ respectively. As explained in previous sections LEDs, op amp, feedback resistor used in fabrication of indigenous sunphotometer are slight miss-match vis-à-vis GLOBE sunphotometer components. Without verifying the reliability of parts direct application of Langley plot method, an absolute calibration method for sunphotometer, cannot be applied because it may generate erroneous results. Calibration of indigenously developed sunphotometer was performed using new improvised method. 
This reference GLOBE sunphotometer was used for calibration of the indigenous sunphotometer. The central idea of our calibration scheme was that the AOT measured by GLOBE sunphotometer and local sunphotometer must agree to within acceptable error range. For selected clear days (mostly post rain clear periods) of months of Oct16 to Feb17, under stable atmospheric conditions, empirical values of $\mathrm{V}_{0}$ were used with data of local sunphotometer to generate AOT matching with AOT obtained with pre-calibrated GLOBE sunphotometer. The set of empirical values of $\mathrm{V}_{0}$ were filtered by using mean deviation and rejecting data having more than $10 \%$ deviation from mean value. The mean of these filtered empirical values were termed as extraterrestrial constant for our local indigenous sunphotometer. This obtained extraterrestrial constant was used to retrieve AOT of local indigenous sunphotometer. The repeatability of calibrations made at different times of the year offers additional evidence that the sunphotometer is equally operateable in different seasonal conditions. This whole calibration scheme can be termed as "modified transfer of calibration method". In original transfer of calibration method sun-photometer of same type are calibrated by comparison of measured direct sun radiation intensity with a reference device, calibrated at MLO LAB.

For determination of $\mathrm{V}_{0}$ of local sunphotometer, simultaneous measurements were made with both sunphotometers (GLOBE and Local) for successive five months from October 16 to February 17. A maximum of 12 readings daily were made with half an hour interval equally distributed for prior and post noon (local) sessions. Later on two days of each month with maximum readings indicating clarity or less aerosol accumulations were selected from this data. Mostly post rain clear days were selected due to expected clarity of weather. By applying the aforementioned calibration technique on this selected data, extraterrestrial constant $V_{0}$ for both the channels was calculated. This calculated $V_{0}$ for local sunphotometer was employed for aerosol optical thickness (AOT) calculations. Graphical comparison of AOT for this calibration period of local sunphotometer with GLOBE sunphotometer and satellite data is given in figure $3 \& 4$ for red and green channel respectively. From the two figures it is obvious that trends of AOT for both the channels of different sources are reasonably similar. In figure 3 (AOT of red channel) the maximum deviations of calculated values of AOT of two sunphotometers is 0.078 and minimum is 0.01 . Similarly for green channel shown in figure 4 the maximum and minimum differences of calculated AOT is 0.05 and 0.005 respectively. The average difference of AOT is 0.04 and 0.02 for red and green channel respectively which is considerably low for observed range ( 0.183 and 0.267 for red and green channels repectively) of AOT for calibration period. To quantitatively qualify our results in current study, the data obtained from (Moderate resolution imaging Spectroradiometer) MODIS satellite has been used. In figure 4 AOT of AQUA and Terra Satellite data for combined deep blue and dark target at $550 \mathrm{~nm}$ is also plotted for comparison. The general variation trend of satellite data in figure 4 is similar to ground based AOT values but spread of deviations from the ground based local sunphotometer values is comparably large (minimum $=0.01$, maximum $=0.146$, average $=0.066$ for Terra and minimum $=0.021$, maximum $=0.159$, average $=0.078$ for Aqua). The primary reason of mismatch is fewer number of real time data points generated at a maximum of three of overpass over the study region by Terra and Aqua satellites in 24 hours. The calculated mean AOT of fewer data points usually differ from ground based measurements. Secondary reasons of disagreements in two data sets are the associated assumptions, estimations and processing algorithm dependency of satellite data.

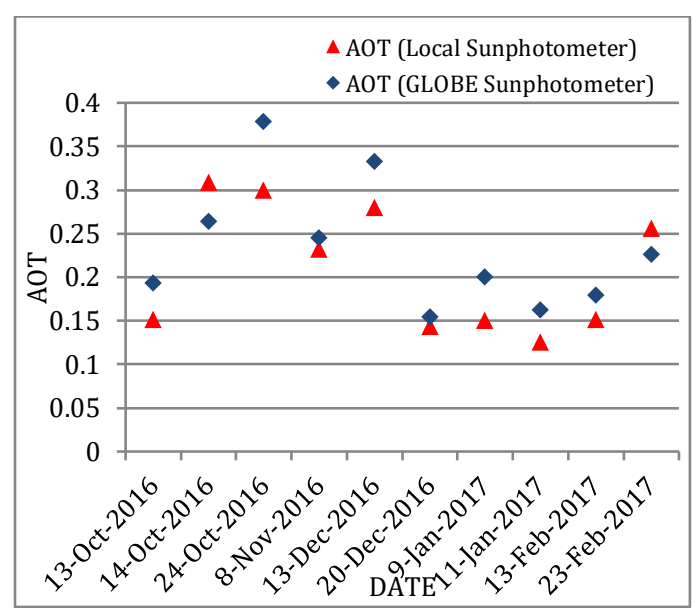

Fig. 3. AOT comparison of GLOBE and local sunphotometer (red channel) of local and GLOBE sunphotometer for selected days of 5 months from OCT 16 TO Feb 17 


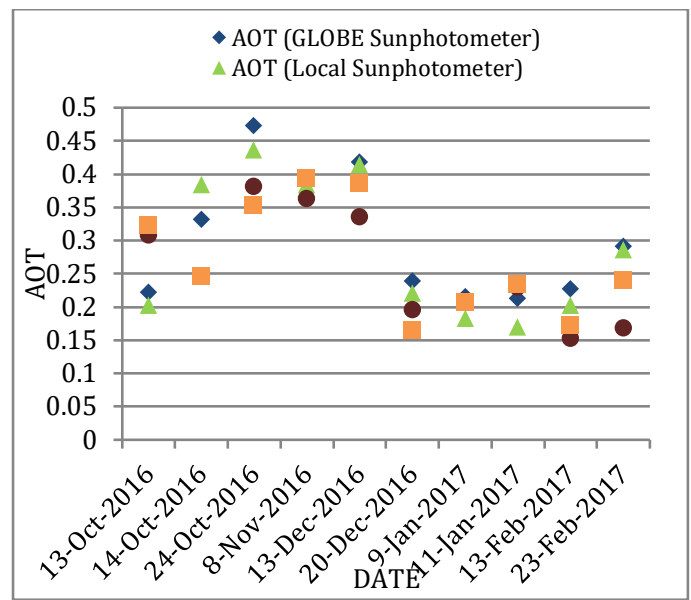

Fig.4. Comparison of AOT (green channel) of local and GLOBE sunphotometer with Aqua and Terra sat AOT for selected days of 5 months from OCT 16 to Feb 17

Satellite data usually falls on lower side as compared to ground based measurements. One of the reasons is that the satellite filters out all other contributions of attenuations of radiation such as ozone, clouds, water vapors, gases etc. before attributing any attenuation to aerosols. Another reason may be the use of LED as a sensor. Spectral response bandwidth of LED is much greater than that of sensors used in satellite with filters. But these differences are often negligible considering the different approximations and methodology used in AOT calculation for sunphotometer and satellites sources.

To assess the coherence between different sets of data correlation was calculated. In figure $5 \mathrm{a}$, correlations between GLOBE and local sunphotometer AOT is given.

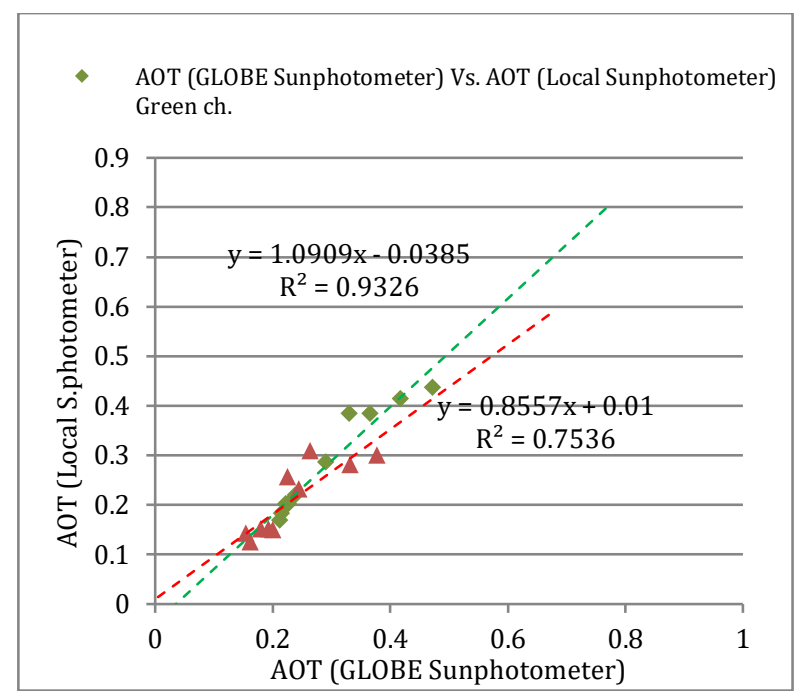

(a)

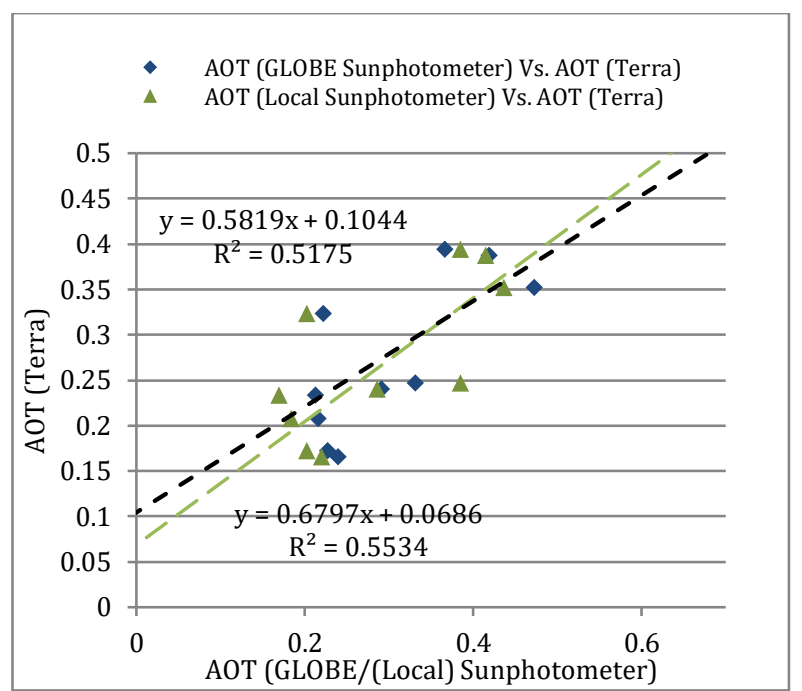

(b)

Fig. 5a. Correlation of AOT obtained by GLOBE \& Local sunphotometer for selected days of Oct 16 to Feb 17. $\mathrm{R}^{2}=0.9326, \mathrm{R}^{2}=0.7536$ for green and red channel respectively. $5 \mathrm{~b}$. Correlation of AOT obtained by comparison of GLOBE \& Local sunphotometer with AOT of Terra Satellite for selected days of Oct 16 to Feb 17. $\mathrm{R}^{2}=0.5534, \mathrm{R}^{2}=0.5175$ for green channel.

\section{3.b. Measurement of AOT by Locally Constructed Handheld sunphotometer for red and Green Channels for July and August 2017}

This newly designed sunphotometer was used for AOT monitoring over Islamabad for months of July and August 2017. The accumulated data is of 35 days with an average of nine readings per day meaning a total of 289 observations per channel for both (local and GLOBE) sunphotometers as shown in figures 6a and 7a for green and red channel respectively. 26 data points were missed either because of cloudy weather or 
some other technical interruptions. The calculated daily averages for each day, based on these readings are given in figures $6 \mathrm{~b}, 7 \mathrm{~b}$ for green and red channels.

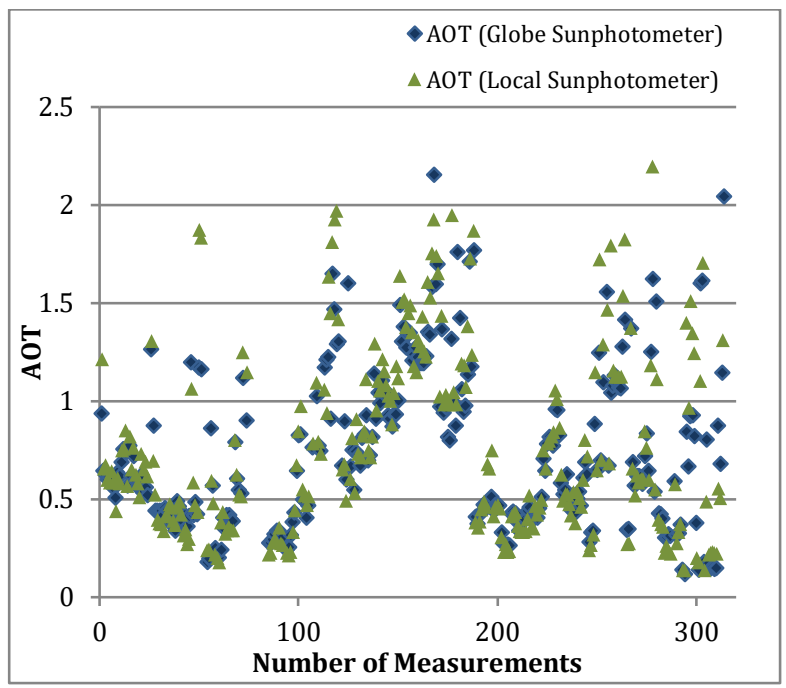

(a)

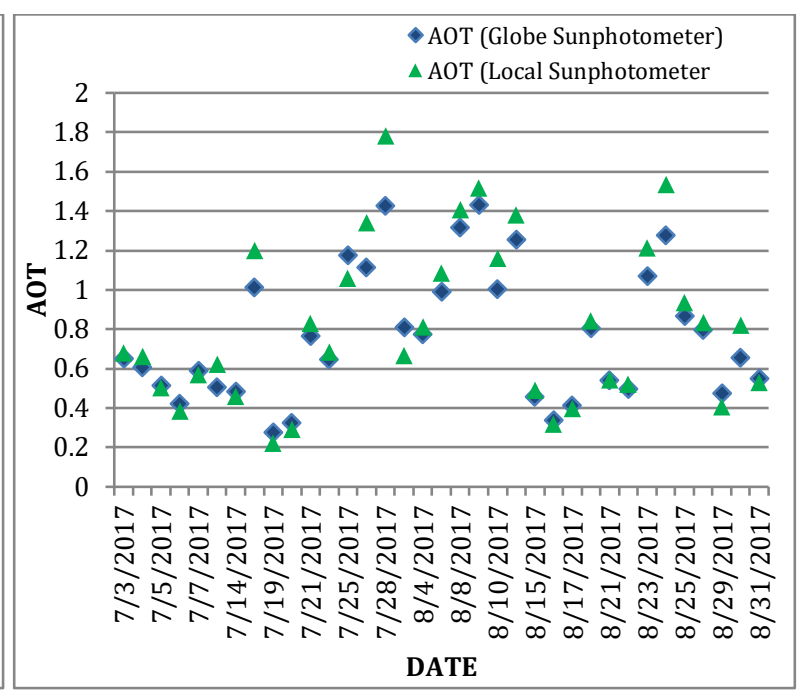

(b)

Fig. 6a. AOT of green $(\lambda=550 \mathrm{~nm})$ channel of GLOBE and Local sunphotometer for month of July, August-2017. 6b. Daily Averaged AOT for green channel of GLOBE and Local Sunphotometer for month of July, August-2017.

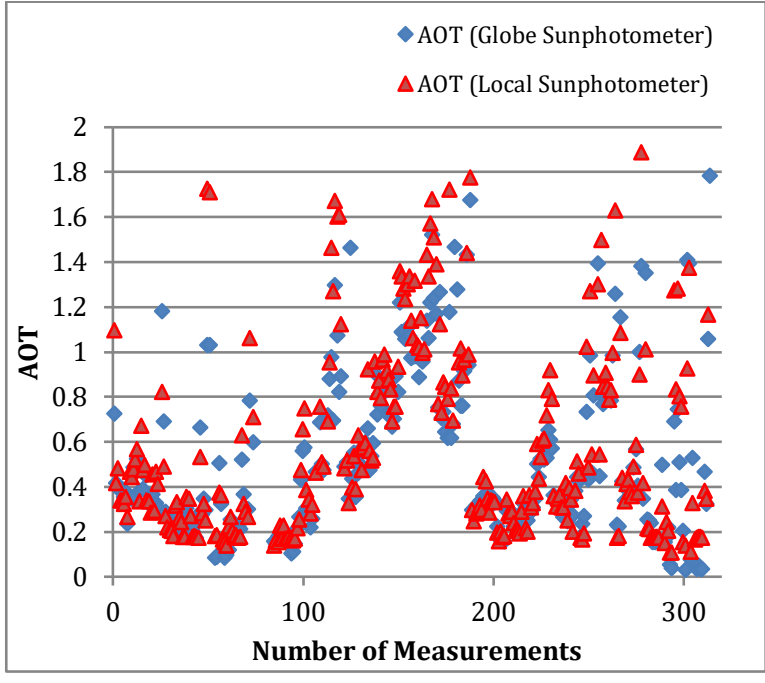

(a)

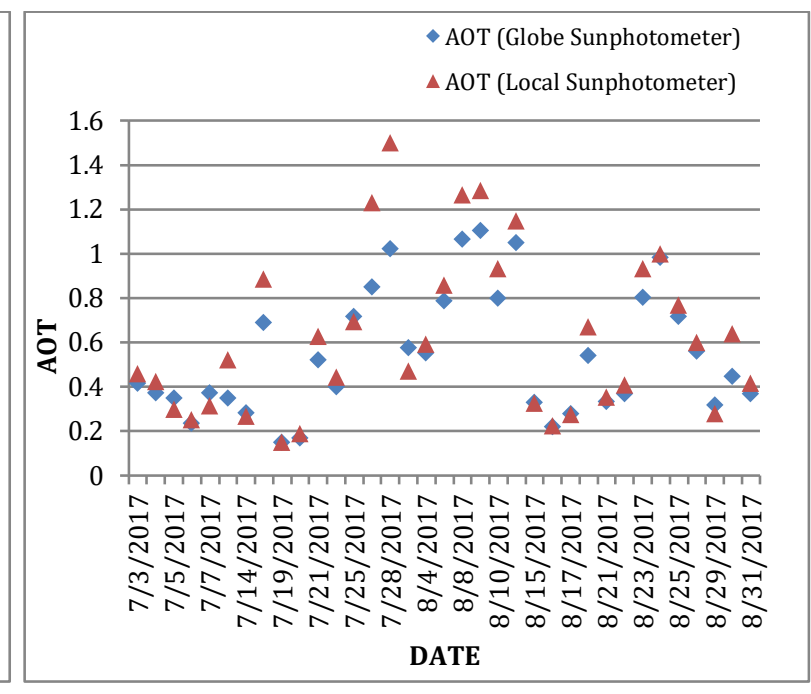

(b)

Fig. 7a. AOT of red $(\lambda=625 \mathrm{~nm})$ channel of GLOBE and Local sunphotometer for month of July, August-2017. 7b. Daily Averaged AOT for red channel of GLOBE and Local Sunphotometer for month of July, August-2017.

The minima of AOT for green channel are 0.11 and 0.13 respectively for GLOBE and local sunphotometers, whereas maximum are 2.15 and 2.19. These considerably large scale AOT variations of 2.04 and 2.06 are indicating fluctuating aerosol compilations over study period of two months. The variability of AOT is compensated to some extent for mean AOT values. The highest mean AOT of single day is 1.78 (green) and 1.50 (red) measured with local sunphotometer on $28^{\text {th }}$ July. From figure $6 \mathrm{~b}$ it is evident that majority of mean AOT values of both sunphotometers for green channel lies in 0.5-1.5. Relatively few mean AOT values (i.e. six each) lies above and below this interval implying that the good clarity and high haziness are sporadic occurrences. Moderate haziness is the dominant behavior of atmosphere for study period. Good clarity of weather is observable from recorded AOT on $19^{\text {th }}$ and $20^{\text {th }}$ July with values of 0.22 (GLOBE), 0.28 (local) for green and 0.15 (GLOBE), 0.19 (local) for red channel respectively. Similarly 0.45-1.25 is the high frequency interval for AOT of red channels for both the sunphotometers. The minima and maxima of this interval for red channel are slightly less than the limits for maximum occurring interval of green channel this is expected as red channel's AOT are usually lesser than green for same atmospheric conditions. 
The accuracy of local sunphotometer data with respect to GLOBE sunphotometer measurements is analyzed using figures $8 \mathrm{a}, 8 \mathrm{~b}, 8 \mathrm{c}, 8 \mathrm{~d}$. In figures $8 \mathrm{a}$ and $8 \mathrm{c}$ the percentage population distribution of relative errors/accuracy [(GLOBE AOT- Local AOT)/GLOBE AOT] of local sunphotometer for green and red channels respectively is given. The mean of this relative error is equal to 0.04 and 0.12 for green and red channels respectively. About $85 \%$ and $74 \%$ of measurements for green and red channels respectively lies within 0.25 of relative error limit. This implies that same turbidity/visibility level can be assigned to area under study based on overall prediction about AOT accumulations in atmosphere by any of two sunphotometers. Correlation plot for GLOBE and local sunphotometer measurements are given figures $8 \mathrm{~b}$ and $8 \mathrm{~d}$. High $\mathrm{R}^{2}$ values $\left(R_{\text {green }}^{2}=0.8927, R_{\text {red }}^{2}=0.877\right)$ are indicative of agreement of constructed device with pre calibrated GLOBE sunphotometer results. For assessment of consistency of measurements process distribution/deviation of error about mean error is plotted in figure 8e and 8f. Figure 8e and 8f depicts symmetrical error distribution about mean error. Therefore it can be concluded that the measurement process was consistent. Majority of errors values are clustered in interval of -0.25 to +0.25 i.e. $83 \%$ and $77 \%$ for green and red channels respectively. The width of error distribution for red channel is considerably greater than green channel indicating comparatively lesser degree of accuracy for this channel. The last few days of month of August showed greater fluctuations in AOT from prior noon to post noon observations. Such high variations in AOT are comparatively rare in month of July. The average AOT of July 2017 and August 2017 for GLOBE sunphotometer is 0.7 and 0.81 for green channel whereas the corresponding AOT obtained through Local sunphotometer are 0.75 and 0.86 respectively. The higher monthly and daily averages of AOT for August may be attributed to usual trend of higher humidity and comparatively lesser rain fall for August than July in region of country. This increase of AOT can be attributed to higher concentration of hanging impurities for constant dry patch of weather. Because of dry spell and heat, the concentration of dust, pollen, bacteria, salt, various pollutants in air as well as concentration of aerosol tend to increase generally [30]. Also higher aerosol accumulation itself is responsible for less rainfall and excessive heat. So its effect is regenerative.

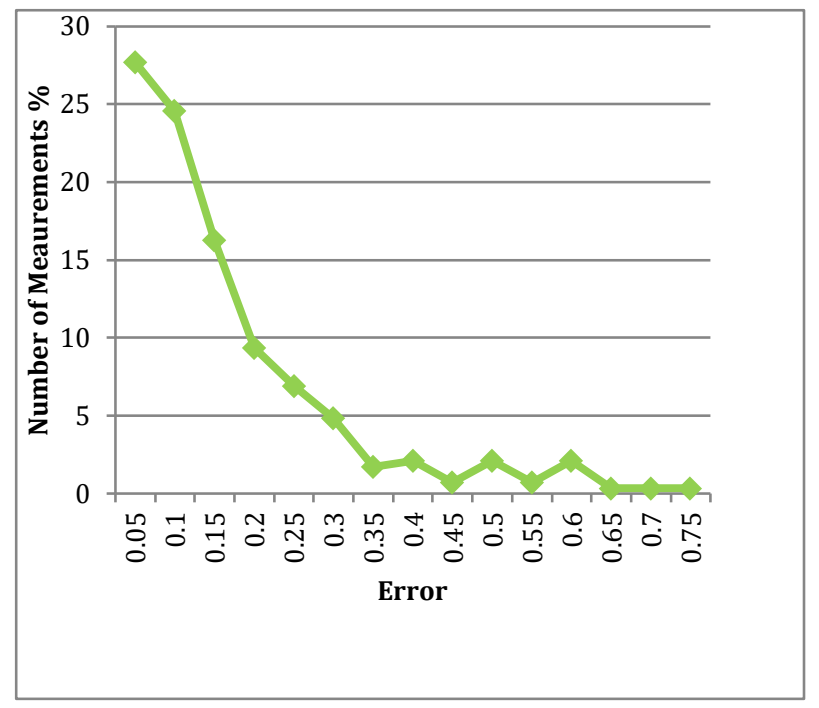

(a)

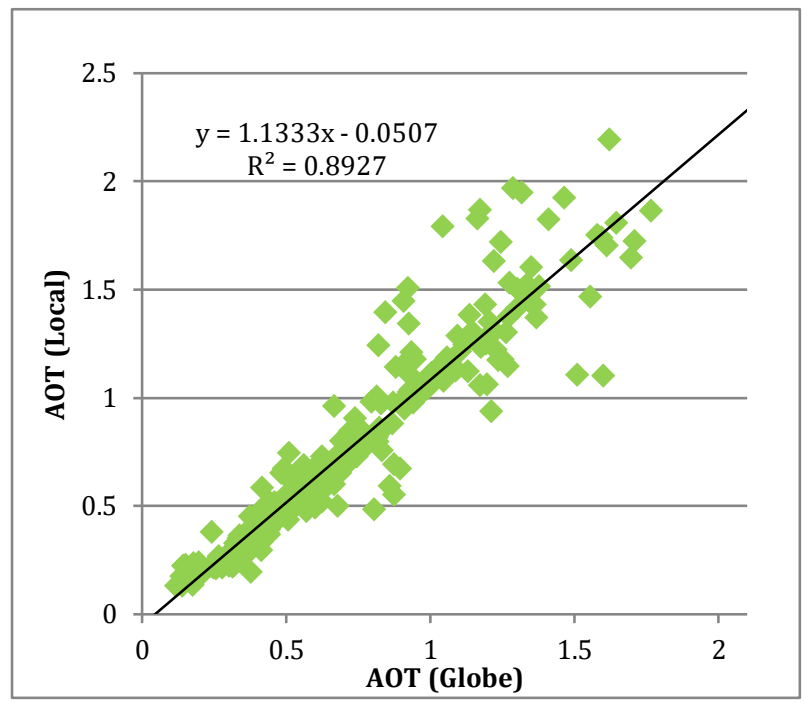

(b)

Fig. 8a. Percentage error distribution (green channel). 8b. Correlation plot (green cannel) 


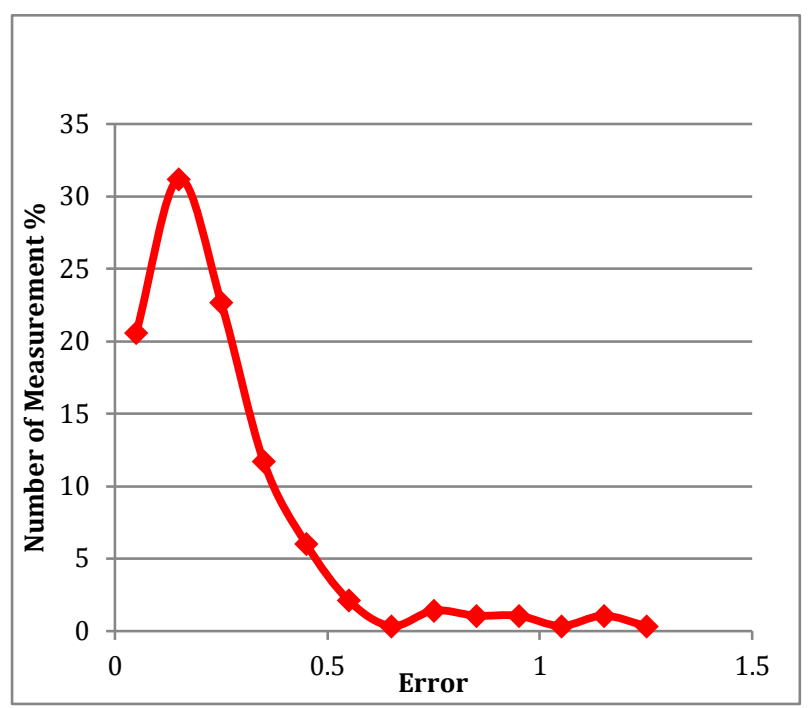

(c)

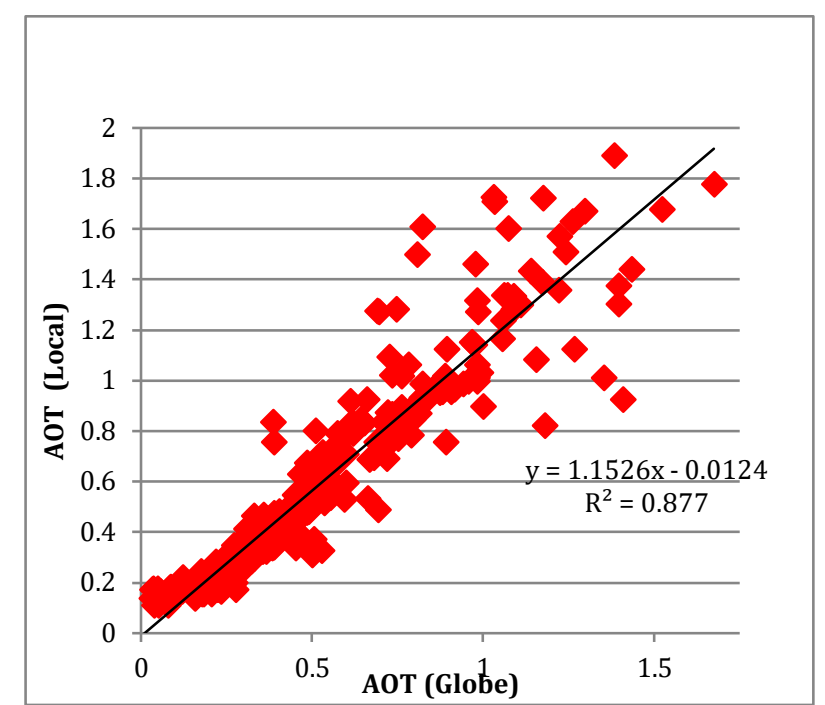

(d)

Fig.8c. Percentage error distribution (red channel). Fig.8d. Correlation plot (red cannel)

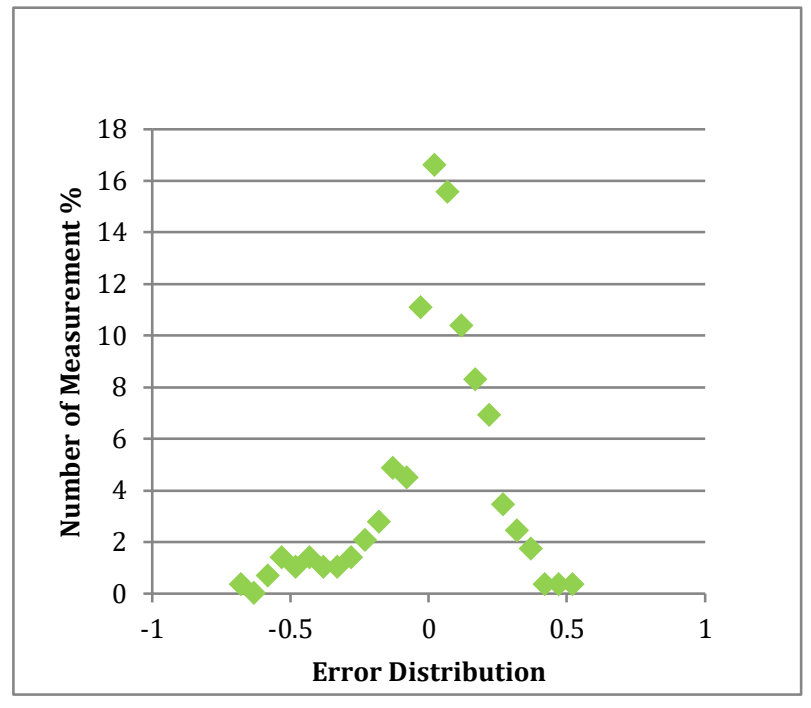

(e)

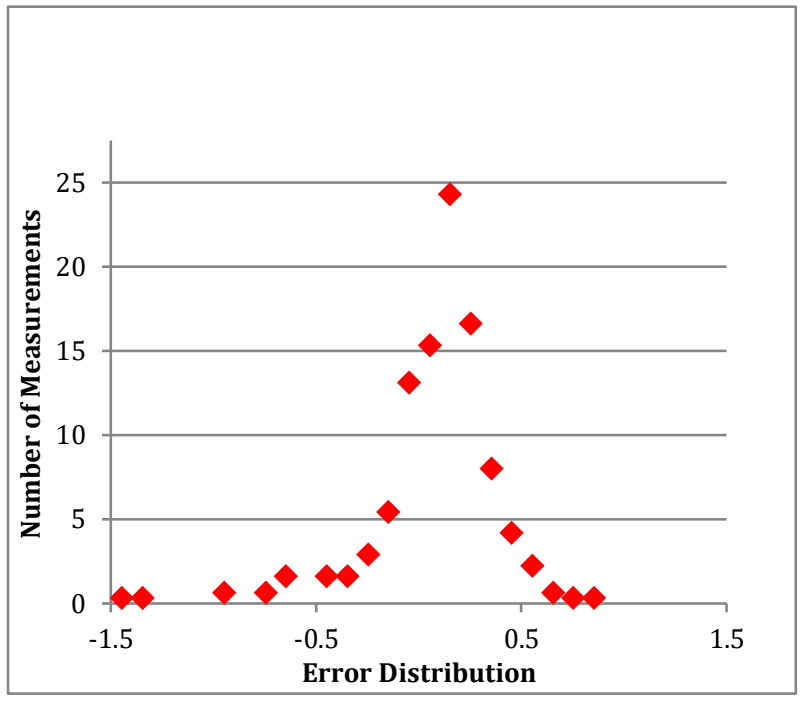

(f)

Fig. 8e. Error distribution about mean error. Fig.8f. Error distribution about mean error

\section{3.c. Calculation of Angstrom wavelength exponent}

Two variables important for characterizing the aerosols are angstrom exponent coefficient $\alpha$ and angstrom turbidity constant $\beta$, related to the Aerosol Optical Thickness $(\tau)$ and central wavelength of detector (LED in this case) employed $(\lambda)$.

$$
\tau=\beta \lambda^{-\alpha}
$$

Here $\lambda=$ wavelength in microns while $\alpha$ and $\beta$ are the Angstrom's exponent and turbidity coefficient, respectively, showing signs of spectral variation depending upon the aerosol physical and chemical characteristics [31]. The Angstrom wavelength exponent $(\alpha)$ is a commonly used parameter to illustrate the wavelength dependence of AOT and to obtain basic information about the aerosol size distribution. It is also an indicator of the relative fine-mode strength [32].

The Angstrom wavelength exponent $(\alpha)$ can be calculated using the AOT $(\tau)$ at two different wavelengths by applying the Volz method, equation 5 


$$
\alpha=-\tau \frac{d \ln \tau}{d \ln \lambda}=-\frac{\ln \frac{\tau_{1}}{\tau_{2}}}{\ln \frac{\lambda_{2}}{\lambda_{1}}}
$$

Calculation of angstrom exponent and atmosphere turbidity coefficient is important for atmosphere monitoring as aerosol size and type are determined with help of these two parameters. The following figures 9a indicate the varying pattern of angstrom exponent for months of July and August 2017 using AOT obtained with local sunphotometer.

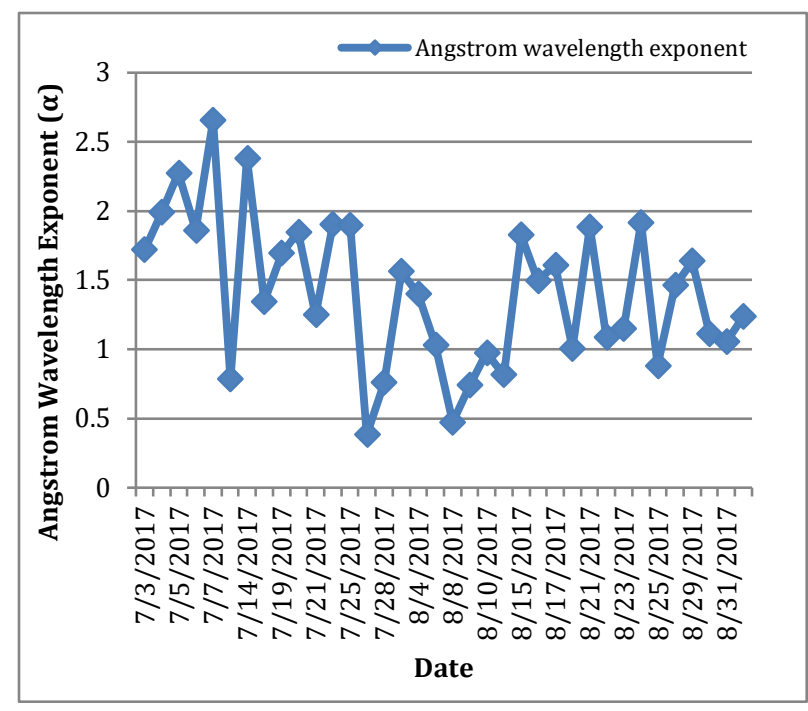

(a)

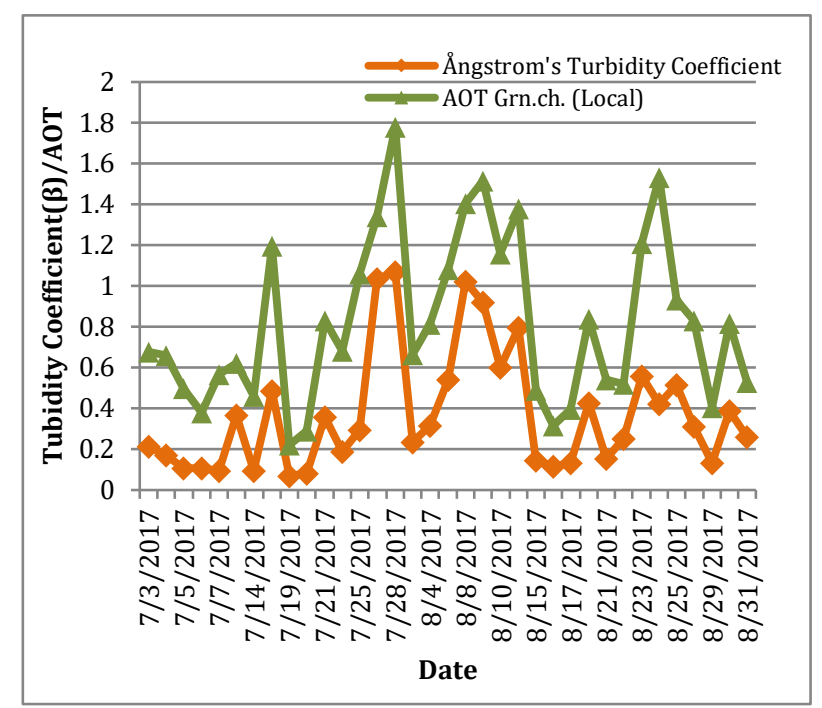

(b)

Fig. 9a. Angstrom exponent for July, August 2017. 9b. Turbidity Coefficient for July and August 2017 with AOT for comparison

The normal range of angstrom exponent spans from 0.5 to 2.5. For relatively less polluted urban atmosphere the average value of angstrom exponent is about 1.5. Our calculated values of angstrom exponent for aforementioned period fall well in the normal range as indicated in figure 9a. The average of angstrom exponent for recorded data is 1.42 , this implies moderately polluted urban atmosphere of area under study. Similar trends about aerosol accumulations in lower tropshere have also been reported by few Mie Lidar based studies of región under study [33]. It is essential to realize that larger values of $\alpha$, when the $\tau$ value for the larger wavelength is much smaller than the $\tau$ value for the smaller wavelength, implying a relatively high ratio of small particles to large $(r>0.5 \mu)$ particles. As $\tau$ for the larger wavelength approaches the $\tau$ for the smaller wavelength, larger particles dominate the distribution and $\alpha$ gets smaller. In accordance with above mentioned criteria if graph of figure 9a is correlated with AOT values of figure 6 and figure 7 it can be concluded that large aerosol have higher concentration for $13^{\text {th }}, 27^{\text {th }}, 28^{\text {th }}$ July $08^{\text {th }}, 09^{\text {th }}, 11^{\text {th }}$ and $25^{\text {th }}$ August, whereas $4^{\text {th }}, 5^{\text {th }}$ and $14^{\text {th }}$ July have substantial fine mode strength. The total variation span of $\alpha$ is 2.27. The urban aerosols mainly comprise of fine constituents, and therefore point toward high values of $\alpha$, although the AOT is very variable, depending on whether the aerosol is more or less polluted [34,35]. Whereas, biomass-burning aerosols are characterized by a turbid atmosphere, with AOT which can reach an limit of 2.5 or even slight higher. The spectral signatures in this case depend on the species of combustible, aerosol age and humidity, but in general large numbers of fine particles shoot up in the atmosphere. Thus higher AOT may assumed to be associated with strong wavelength dependence, that is, high $\alpha$ values above $1.5[36,37,38]$.

Simplified definition of Atmospheric turbidity is the optical depth due to aerosols in the entire vertical column of the atmosphere, and according to Angstrom, the relationship between turbidity and wavelength follows a power law. Although other relations in addition to the power law might be considered, Angstrom's relation seems to be a good representation of aerosol that has a wide variety of origin [39]. Turbidity coefficient, $\beta$ corresponds to the optical depth at unit wavelength $(1 \mu \mathrm{m})$ and is related to the aerosol loading. The atmosphere's clearness is judged with the help of Turbidity coefficient $\beta$, for clear atmosphere $\beta \sim 0.1$ and as haziness increases $\beta$ approaches 0.2 or slightly higher values. From figure $9 \mathrm{~b}$ it is obvious that $19^{\text {th }}$ and $20^{\text {th }}$ July are clearest day for monitoring period with $\beta=0.07$ and $\beta=0.083$ respectively. The corresponding values of AOT are 0.22 and 0.288 for green channel of local sunphotometer. Mean turbidity 
for the observation period was 0.37 and variation interval (difference of minimum and maximum recorded values) of $\beta$ is 1.0. The principal factor in determining large fluctuating $\beta$ trends is relatively high humidity and moderate to high monsoon rain events of July and August.

\section{Conclusion}

This study spanning over two intervals firstly the calibration period (Oct 2016-Feb 2017) and secondly the study period (July, August 2017) has utilized an indigenously designed sunphotometer along with precalibrated GLOBE sunphotometer for aerosols monitoring of Islamabad (Pakistan) region. It has demonstrated that locally developed LED based hand held dual channels sunphotometer is capable of providing significant, reliable results to probe the atmosphere with reliable aerosol data. The results additionally confirmed that locally constructed hand held sunphotometer can efficiently be calibrated by using the Transfer of Calibration method with a reference standard pre calibrated GLOBE instrument. AOT measurement with GLOBE and indigenously developed sunphotometer yielded consistent results for calibration period spanning over five months from Oct 2016 to Feb 2017. The corresponding $\mathrm{R}^{2}$ values for GLOBE vs local sunphotometer generated AOT were 0.75 and 0.93 for red and green channels respectively during calibration period. Whereas similar comparison with MODIS (Terra) data gave $\mathrm{R}^{2}$ values value around 0.55 falling in the previously reported range for comparison between ground and satellite based monitoring. This shows that LED based sunphotometer provides results similar to those of a much more costly instrument that uses expensive interference filters and detector. It is also much more robust, less costly and portable than other AOT measurement instruments.

Further study of AOT for study period of July, August 2017 with GLOBE and local sunphotometer revealed fluctuating AOT trends with minima and maxima reaching 0.13 and 2.19. The mean AOT of July and August 2017 is 0.75 and 0.86 for red and green channels respectively. The correlation between the two sunphotometer data was at $\mathrm{R}^{2}=0.85$ and $\mathrm{R}^{2}=0.87$ for red and green channel respectively, slightly higher than calibration period. The consistency of device and operations was also scrutinized through error analysis and has been found satisfactory. The average daily Angstrom parameters $\alpha$ and $\beta$, have also been reported. The average of angstrom exponent for recorded data is 1.42 , this implies moderately polluted atmosphere of area under study. Larger aerosols have higher concentration for $13^{\text {th }}, 27^{\text {th }}, 28^{\text {th }}$ July $08^{\text {th }}, 09^{\text {th }}, 11^{\text {th }}$ and $25^{\text {th }}$ August, whereas $4^{\text {th }}, 5^{\text {th }}$ and $14^{\text {th }}$ July has substantial fine mode strength. On the basis of obtained Turbidity coefficients $19^{\text {th }}$ and $20^{\text {th }}$ July can be termed as the clearest days for monitoring period with $\beta=$ 0.07 and $\beta=0.083$ respectively.

From the extensively satisfactory results it is conclude that indigenously developed LED based sunphotometer offers a precious source of information with simplified operations for proposed atmospheric monitoring network across Pakistan.

\section{Acknowledgements}

Authors gratefully acknowledge the MODIS team for providing the Level-2 data products.Contribution by lab staff throughout this research activity is also greatly appreciated. 